\title{
KOHLER'S DISEASE
}

\author{
By M. J. Cox, M.B., B.S.(LoND.) \\ Late Senior House Officer to the Departments of Orthopaedic and Plastic Surgery, The Hospital for Sick Children, \\ Great Ormond Street, London, W.C.I
}

This paper describes the presentation, diagnostic features and outcome in relation to treatment of 55 patients with Kohler's disease of the tarsal navicular (scaphoid) who attended The Hospital for Sick Children, Great Ormond Street, between 1936 and 1956.

Although Kohler described this condition in I908, Kidner and Muro were able to report only I04 cases from the world's literature in 1924. This series is the largest hitherto reported from one hospital.

The nature of the disease is obscure but it is generally regarded as an osteochondritis due to an avascular necrosis of a special type (Burrows, 1941).

\section{The Normal Radiological Development of the Navicular}

Karp (1937) followed the development of the normal foot radiologically in 25 boys and 25 girls. He showed that the osseous nucleus of the navicular appeared between the ages of 18 months and two years in girls, and between two and a half and three years in boys. When the navicular developed late it was often irregular in shape, dense and flattened and sometimes arose from multiple ossific centres. Some caution must therefore be exercised in making the diagnosis of Kohler's disease on radiological appearances alone.

\section{Clinical Material}

There were 55 patients, of whom 42 were boys and 13 girls. The sex ratio is similar to that found by Karp (1937), Carmera and Prignacchi (1955), and resembles that in Perthes' disease.

The age of onset of symptoms is shown in Tables IA and IB which indicate that the disease usually presents later in boys than girls but a group of boys affected under the age of three is exceptional and unexplained.

The right foot was affected in $2 \mathrm{I}$ patients, the left in 23 and the disease was bilateral in 11 .

\section{Presenting Symptoms}

The commonest early symptom was pain in the foot or ankle but some presented with a limp, a peculiar gait, swollen feet or pain in the knee (see Table 2). The disease was symptomless and found by chance in three patients, while seven of the II patients affected bilaterally had symptoms in one foot only. The age of the patient did not affect the presence or severity of symptoms. The average duration of symptoms in $5^{\circ}$ patients was I 3 weeks.

\section{Physical Signs}

There were no physical signs in $3 \mathrm{I}$ of the 55 children. Six children had feet which were hot, red, swollen and tender, while a further ro had feet which were swollen only. In two there was tenderness over the navicular but in only one was there limitation of movement at the mid-tarsa joint. Two children had knock-knees, one flat fee and two had wasting of the calf.

\section{Radiographic Features}

The diagnosis was confirmed by radiographs in all cases except for some patients, first seen before the war, whose radiographs were destroyed but for whom a radiological report was available. In 24 , serial radiographs allowed a study of the radiographic features and their relationship to symptoms.

The sequence of $\mathrm{X}$-ray changes is well described by Greenwood (1928). The initial change is an increase in density of the navicular; this increased density is at first uniform but then becomes irregular. The bone then becomes smaller than normal, flattened and fragmented. These changes occur over a period varying from three to nine months. The bone then starts to reform by laying down new bone peripherally until the only abnormalities are a central density and irregularity of outline. The central density disappears and finally the bone becomes regular in shape. This occurs usually between 18 months and three years from the onset of symptoms. Brailsford (1953) remarks that an initial change is general rarefaction of the bones of the foot but this was not seen in these patients.

Symptoms occurred in only one patient before 

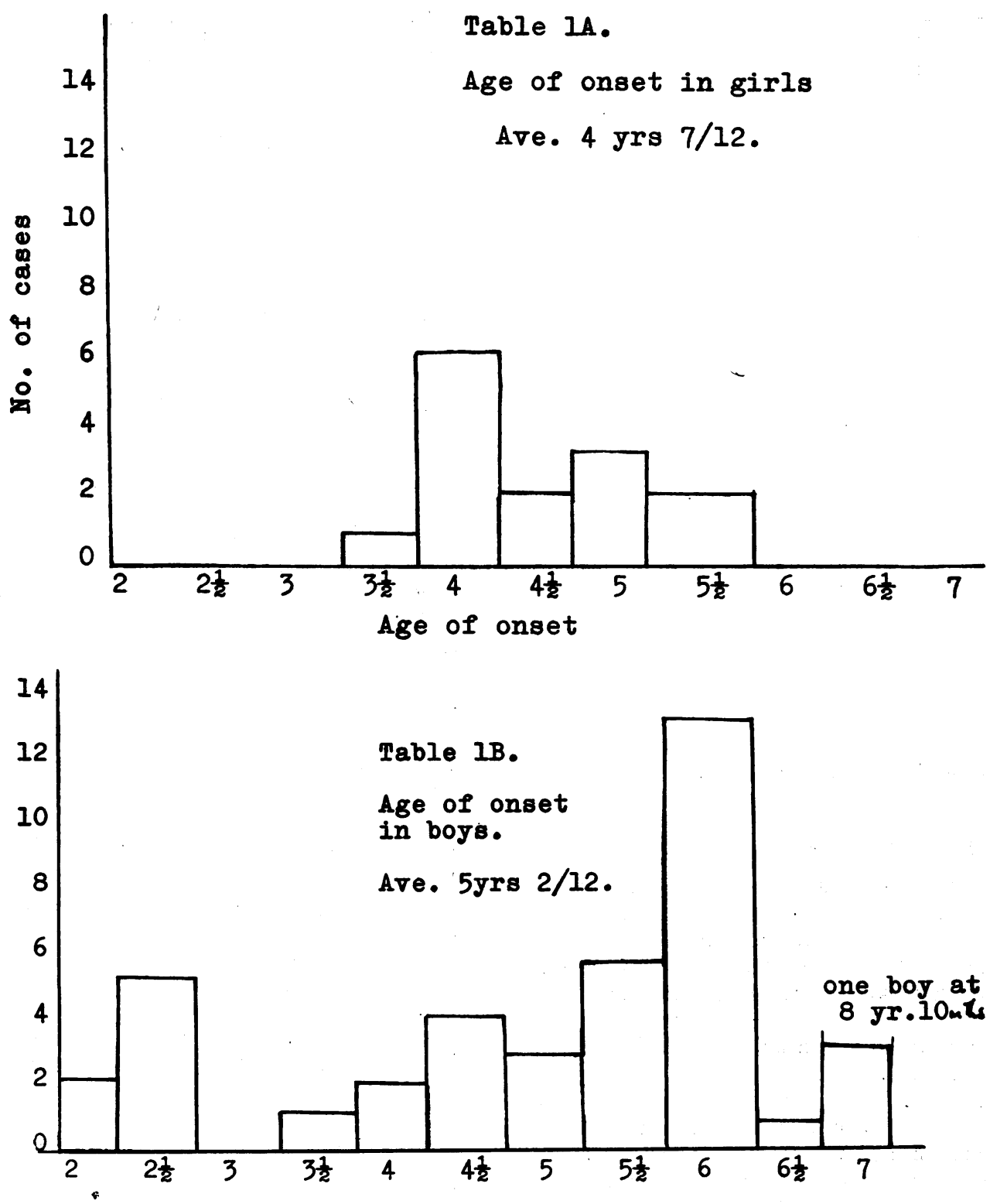

radiological changes. This unusual happening has also been noted by Iles (quoted by Brailsford, 1953). In two the symptoms and X-ray appearances worsened, and in 19 they improved coincidentally, while in three the symptoms improved as the radiological appearances deteriorated.

\section{Methods of Treatment and their Effect}

Fourteen children were not treated. Of these, two did not visit the hospital again and three were symptom free on diagnosis. Nine had mild symptoms, which lasted less than a fortnight in six but persisted for two to six months in the other three.

Wedged shoes were prescribed four times and in one child a caliper was also used. Of these, two were rapidly relieved, but in the others mild symptoms persisted for four and 18 months.

The feet of five children were strapped, giving quick relief in two but the remainder were painful for up to four months, one being put in plaster at this time.

A below-knee walking plaster was used for 32 children and retained initially for less than six 


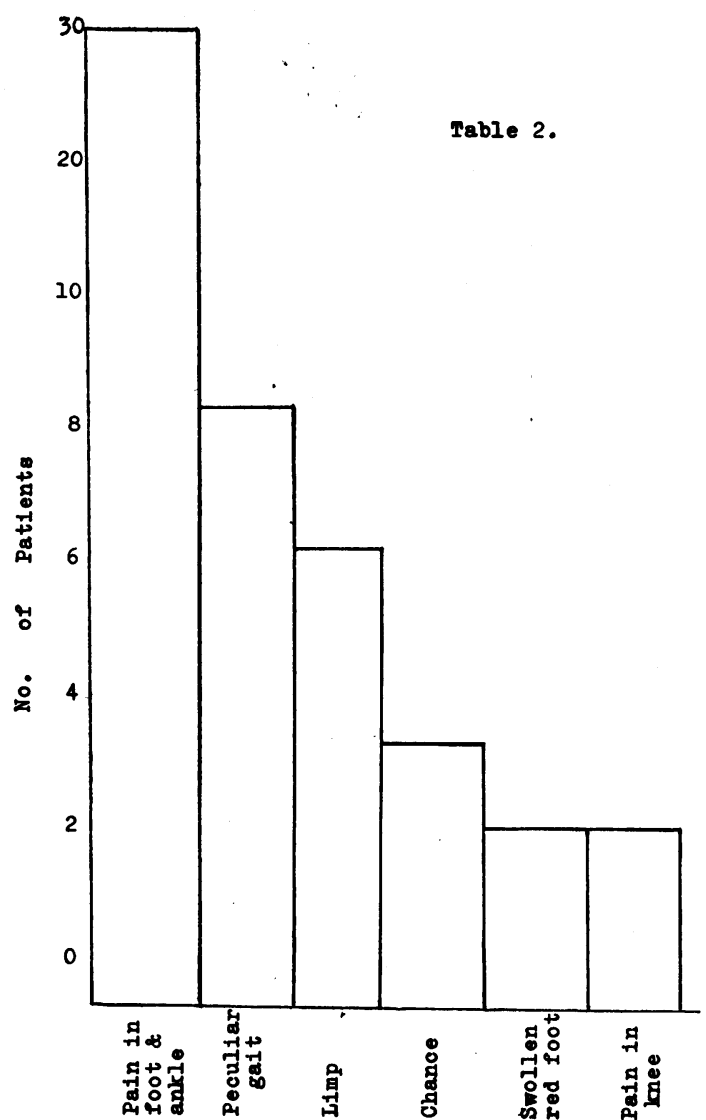

weeks in 17 patients and up to seven months in the remaining 15 . Of the 17 children immobilized for up to six weeks, nine were symptom free at the end of this time, two had mild symptoms only, and five with continuing pain had their plasters reapplied for a further two months before their symptoms disappeared. One child left the district and was not followed.

Of the 15 children kept in plaster for longer periods, six were symptom free throughout their immobilization and five very soon became symptom free but, nevertheless, remained in plaster for two to seven months. Three children, whose symptoms continued for up to four months, became rapidly symptom free on removal of the plaster (one of these children sustained a march fracture three months later). One child, whose symptoms continued while in plaster for three months, left the district and was not followed.

\section{Follow-up}

Thirty-one of the 55 patients were traced. Letters were received from three who reported their feet to be normal. The remaining 28 attended the hospital and were examined clinically and radiologically.
The period of follow-up from the onset of symptoms is shown in Table 3 .

TABLe 3

Years from onset

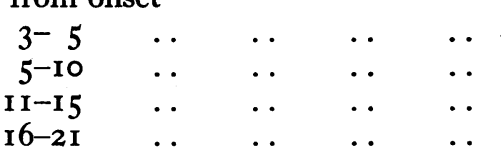

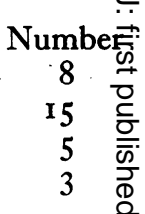

Of these 3 I patients 26 are free of symptoms an ڤ $^{2}$ signs, many are unable to remember which foo 5 was affected; five have minor symptoms, such as aching feet or occasional instability of the ankles which may well be coincidental.

The X-rays are normal in 26 patients, but in twक्ष boys, seen five and seven years after the onset of: symptoms, the outline of the navicular is stilf irregular.

There was no evidence that any form of treater ment or even lack of it influenced the ultimate result, for this was invariably excellent as in those of Waugh (1956), Carmera and Prignacchi (1955) and Karp (1937).

\section{Aetiology}

Eight of the 55 patients remembered an injuryd which coincided with the onset of pain in four, क्रिष्ठ in the remainder preceded the presenting symptents by up to two months. One had bilateral disesse but had injured one foot only. This smald number is probably without significance.

A family history was obtained from 40 patient? and in none was there a relation with Kohler'\& disease or any other osteochondritis.

One patient in this series had Perthes' disease $\overrightarrow{\vec{\Theta}}$ and two had bilateral osteochondritis of the first cuneiform in addition to Kohler's disease (cF Donohue et al., I948). One patient with dysplasia. epiphysialis multiplex and two with congenital vertical talus showed changes identical with: Kohler's disease (Lloyd-Roberts and Spences 1957). A patient of Greenwood's (1928), with. $\mathrm{X}$-ray changes identical to those of Kohler's disease, had to have his foot amputated; sub sequent histology showed typical tuberculouঙ material.

There is no helpful histological or bacteriologicafmaterial available, but the higher incidence in boys and self-limiting course of the disease make infec tion an unlikely cause. The facts that retarde\& ossification may simulate Kohler's disease, ang that the disease is less common in girls, in whom the navicular ossifies earlier, suggests that the cone dition may be a variant of normal development bu骠 the group of younger boys affected is difficult tiq explain on this basis. 


\section{Management}

As the disease has such an excellent long-term prognosis even without treatment, treatment should be symptomatic. When symptoms are severe enough to justify treatment a below-knee walking plaster may be used for initially six weeks. If, at the end of this time, symptoms have been relieved, no further treatment is necessary and the child may be allowed to run free. If symptoms persist or recur then plaster may be reapplied for a further period.

There is no evidence that wedged shoes, strapping, physiotherapy or prolonged immobilization have any value.

An X-ray is essential for diagnosis and to exclude other causes of pain in the foot. If the symptoms are mild or disappear rapidly, only the initial X-ray is necessary but if they continue or worsen further $\mathrm{X}$-rays should be taken to exclude the very rare possibility of infection. There is neither necessity nor justification for continuing to see the child until the bone is radiographically normal.

\section{Summary}

I. Fifty-five cases of Kohler's disease seen at the Hospital for Sick Children, Great Ormond
Street, between 1936 and I956, are described.

2. The age of onset, sex incidence, presenting symptoms, physical signs and the influence of treatment are discussed.

3. A follow-up of $3 \mathrm{I}$ patients seen between three and 21 years from the onset of symptoms is described.

4. The aetiology is discussed.

5. A plan of management is suggested.

\section{Acknowledgments}

I should like to thank Mr. G. C. Lloyd-Roberts for his help and encouragement and for permission to examine patients under his care. I am grateful to Mr. Denis Browne and Mr. G. H. Macnab for allowing me to include their cases in this review.

\section{BIBLIOGRAPHY}

'BRAILSFORD (1953), 'The Radiology of Bones and Joints,' London.

BURROWS (I94I), Brit. F. Surg., 29, 23.

CARMERA and PRIGNACCHI (1955), Minerva ortop. (Torino), 6 (8 and 9$)$, 340.

DONOHUE, DONOHUE and ZIMMERMAN (I948), $\mathfrak{f}$. Bone $\mathfrak{f t}$ Surg., 30A, 780.

GREENWOOD (1928), Brit. $\mathcal{F}$. Surg., 15, 245.

KARP (1937), f. Bone $\mathfrak{F t}$ Surg., r9, 84.

KIDNER and MURO (r924), $\mathcal{F}$. Amer. med. Ass., 83, 1650.

KOHLER (1908), Miunch. med. Wschr., 55, 1923.

LLOYD-ROBERTS and SPENCE (I957), in print.

WAUGH (1956), Proc. roy. Soc. Med., 49, 965.

\section{HEPATIC DISEASE}

(Postgraduate Medical Journal)

Price: 3s. 11d. post free

\author{
JAUNDICE \\ Sheila Sherlock, M.D., M.P.C.P. \\ HEPATIC COMA \\ J. M. Walshe, M.A., M.R.C.P. \\ SURGICAL TREATMENT OF PORTAL \\ HYPERTENSION \\ A. I. S. Macpherson, Ch.M., F.R.C.S.E.
}

WILSON'S DISEASE

A. G. Bearn, M.D.

\author{
ASCITES IN LIVER DISEASE \\ Michael Atkinson, M.D. (Lond.) \\ M.R.C.P. \\ PSYCHIATRIC ASPECTS OF LIVER
DISEASE \\ Esther A. Davidson, M.R.C.P.Ed., and \\ W. H. J. Summerskill, M.A., M.R.C.P.
PERCUTANEOUS PORTAL
VENOGRAPHY
David Sutton, M.D., M.R.C.P., F.F.R.

Published by

THE FELLOWSHIP OF POSTGRADUATE MEDICINE

60, Portland Place, London, W.1 